\title{
How Pre-tenure and Tenured Faculty Can Engage Undergraduates in Publishable Research
}

\author{
Albee Therese O. Mendoza ${ }^{1 *}$ and Jeannie A. Golden ${ }^{2}$ \\ ${ }^{1}$ Department of Psychology, Wesley College, Dover, DE, United States, ${ }^{2}$ Department of Psychology, East Carolina University, \\ Greenville, NC, United States
}

Keywords: career stage, pre-tenure faculty, tenured faculty, early career faculty, late career faculty, publishing, undergraduates

Differences in career stage may influence work stress and job satisfaction (Olsen and Crawford, 1998), which in turn can impact attitudes about recruiting, managing, and mentoring undergraduates in publishable research endeavors. Written from the perspectives of a pre-tenure faculty member (i.e., in 4th year) at a primarily teaching institution (PTI) and a tenured faculty member (i.e., in 38th year) from a large research university (RU), this paper discusses obstacles faced by professors at different career stages and institutions while working on publishable research with undergraduates as well as strategies to overcome these obstacles.

\section{PRE-TENURE FACULTY}

OPEN ACCESS

Edited by:

Jeanine Lee McHugh Skorinko, Worcester Polytechnic Institute,

United States

Reviewed by:

Jeanine Stefanucci,

University of Utah, United States

*Correspondence:

Albee Therese O. Mendoza

albee.mendoza@wesley.edu

Specialty section:

This article was submitted to

Educational Psychology,

a section of the journal

Frontiers in Psychology

Received: 01 December 2018

Accepted: 14 January 2019

Published: 06 February 2019

Citation:

Mendoza ATO and Golden JA (2019) How Pre-tenure and Tenured Faculty

Can Engage Undergraduates in

Publishable Research.

Front. Psychol. 10:111.

doi: 10.3389/fpsyg.2019.00111
Early career psychologists (ECPs) are faculty members working in their academic position within 7 years and have not obtained tenure (Keeley et al., 2013). For ECPs in RUs/PTIs, an important first step is to ask senior faculty how mentorship and publication fit with the department's expectations (Crawford, 2013). In PTIs, the pressure to "publish or perish" is not as salient as in RUs; however, ECPs are still eager to collaborate and publish with students for various reasons. One motivation is to include publications in their evaluation portfolio.

However, ECPs may not have much experience with publishing in general. One strategy to increase their knowledge of the publication process and the quality of writing required by journals, ECPs can read resources tailored to writing publishable research reports (e.g., Carver, 1984; Fallon, 2016). To boost their publication knowledge as well as enhance their portfolios, ECPs can volunteer in journals with open calls for reviewers, with some (e.g., Psi Chi, 2018a) not requiring any publication experience. This may have an added benefit later on in that being a reviewer for a journal may lead to increased confidence when mentoring a student who is publishing in that journal.

As an extension of their publishing inexperience and because they may not have a reputation at their institution, ECPS may have trouble finding students to work with on publishable research. In RUs, projects are often mentor-centered and students may take on roles as research assistants. Thus, a strategy for ECPs in RUs and PTIs is to recruit students directly from the courses they teach. ECPs can also reach out to colleagues and have them send students their way. In PTIs, projects are often student-generated and perhaps faculty mentors do not have course releases to do research nor have research labs. Thus, a strategy is to seek out advanced graduate-school bound undergraduates (Starke, 1985) such as those in capstone courses or honor thesis classes and encourage them to collect data and publish their work with the ECP as mentor.

However, ECPs (perhaps due to their eagerness and inexperience) may have uninformed expectations. ECPs may trust senior-level honors students to complete tasks without much involvement, due to the expectation that these students possess a positive attitude, emotional 
maturity, and strong work ethic.However, students may not match the expectations nor demonstrate the behaviors needed for the publication process, so there may be disappointment, anger, and regret when a project does not get published. One strategy to clarify expectations/behaviors is to develop written research learning contracts (Mabrouk, 2003) which clearly describe and may include the objectives of both parties, the tasks involved, deadlines when tasks are due, what happens if deadlines are not met (e.g., will the project continue after graduation?), what behaviors are expected on both ends (e.g., how soon should emails be answered?), and what happens if behaviors are not demonstrated (e.g., how will this impact letters of recommendation?). Another strategy to set the stage from the get-go is to write an open letter (McGuire, 2008) to any potential student outlining expectations/behaviors. If a student is taking a course in which a publication-ready manuscript is the end product, a clear rubric (Clabough and Clabough, 2016) can outline tasks related to publication (e.g., read submission guidelines) as well as expectations for conduct (e.g., asked questions in a timely manner).

Another issue related to student expectations/behaviors is that ECPs may not yet have adopted their own managerial style (Crawford, 2013). They may not have learned the necessary skills in graduate school nor had enough opportunity to practice these skills. One strategy for learning a managerial style is to solicit input from senior colleagues, from within and outside the institution; and the earlier, the better (Ponjuan et al., 2011). Senior faculty can provide ECPs different models of what works best for them and for the institution when publishing with students (e.g., benefits of being more hands-off vs. more involved) as well as give concrete examples of what they did to help a student successfully publish their work. They can also direct ECPs to resources to help manage and mentor student researchers (e.g., Narendorf et al., 2015; Shanahan et al., 2015).

Due to the pressure of evaluation and the desire to impress their students and colleagues, ECPs may take on too much, especially in the years leading up to tenure. Professionally, a strategy to boost both scholarship and teaching in their portfolio is to integrate their research in their teaching. One way is to incorporate the data collected from their publishable research as class exercises on data analysis, APA style, ethics, etc. Another way is to teach courses that may provide the perfect arena for generating research based on the course content or the structure of the course, which then could spurn student interest in research and eventually recruit mentees. A strategy to boost both scholarship and service in their portfolio is for ECPs to become student organization advisors. An ECP can encourage students who have high academic standings such as those in Psi Chi (Lechago et al., 2009) to work together on a publishable research project. Personally, ECPs may feel that they need to prove their worth to others and thus, they may take things personally and believe that what their students do or do not do (i.e., successfully publish or not) is a reflection on their ability or ineptitude. One strategy is to reach out to peers, either within and/or outside the institution, who are trustworthy and like-minded. With this support system, ECPs can be honest about personal and professional challenges, commiserate on like experiences, and brainstorm solutions to problems. If talking about sensitive issues with colleagues within the department/institution is uncomfortable, another strategy is to participate in a formal mentoring program (e.g., Finley, 2018) and discuss the aforementioned issues with more seasoned mentors outside the institution.

\section{TENURED FACULTY}

Late-career faculty (LCPs) are faculty members working in their academic position for 20 or more years and have achieved tenure (Baldwin and Zeig, 2013). In RUs and some PTIs, posttenure review serves as a motivator for LCPs to continue to be engaged in teaching, scholarship, and service activities. In terms of scholarship, LCPs may have more time to work with undergraduates on publications by having course preparations done. They may also have existing data that need to be analyzed, and students may be more committed to working on a publication if they do not have to collect data from scratch nor go through the IRB process.

Due to their established network, LCPs may have increased connection to funding sources. Einarson and Clarkberg (2004) found that outside funding increased the likelihood of faculty including undergraduates in their research. However, funding sources (e.g., Society for the Teaching of Psychology, 2018) may disappear after the early career "clock" has run out or after one gets tenure. Thus, it benefits LCPs to know what funding sources are available to them regardless of career stage. For example, many conferences have undergraduate research awards and/or venues specifically designed for student presentations (e.g., American Psychological Association, 2018). Additionally, funding for student-led research as well as travel to professional conferences may be available from funding through student organizations (e.g., Psi Chi, 2018b). LCPs in RUs and some PTIs may have access to participant pool management systems (e.g., SONA) and/or online survey methods (e.g., SurveyMonkey) paid for by either internal funds or external grants, which can support data collection and save time.

Due to their experience, LCPs in RUs/PTIs may use their time more efficiently when engaging undergraduates in publishable research by choosing students wisely. LCPs at RUs and some PTIs who have lost funding for costly graduate assistants can fill this gap with highly trained and skilled undergraduates. If undergraduates are identified early in their college years, they will actually be available longer than master's level students. As these undergraduates assist, a natural vetting process takes place. It is easy to identify those undergraduates who are organized, meticulous, timely, and committed to doing the job well and getting it done; and ultimately perfect candidates for co-publishing. In addition, LCPs in RUs/PTIs are probably more adept at instructing, guiding, scaffolding, and knowing when to cut their losses.

Since LCPs in RUs/PTIs may have demands on their time with more administrative and leadership responsibilities, they may not have as much contact with undergraduates, particularly if they are not teaching undergraduate classes. Strategies to overcome this 
lack of contact include developing a website for their research lab (more likely in RUs) or listing their research interests and previously completed published projects on a faculty website. LCPs in RUs and some PTIs who developed research labs, that are layered with both undergraduate and graduate students at various levels of their college years, can provide valuable and sustainable mentoring to undergraduates who are interested in and capable of publishing. Thus, in RUs where LCPs may not be teaching undergraduates, often their graduate students do teach undergraduate students and may inform these students about the research that they themselves are involved with in the lab of their faculty mentor. In RUs/PTIs, another strategy is being a guest speaker for introductory courses and student organizations (e.g., Psychology Club) and emphasizing the importance of research productivity in the difficult challenge of gaining admission to graduate school as well as the advantage of research-related skills (e.g., collaboration, project management) in the workplace. Students can also be reminded that engaging in publishable research with faculty can lead to stronger letters of recommendation.

Some LCPs, despite systemic disincentives and heavy workloads, still decide to mentor undergraduates in the research process. Individuals with high levels of job satisfaction and a strong commitment to their place of employment are more willing to voluntarily engage in activities outside their specific job-related duties (e.g., mentoring undergraduate students) if they perceive it as having relevance to their work (Mamiseishvili and Rosser, 2010). For LCPs in RUs/PTIs, perhaps a strategy to have high job satisfaction is to think back to previous students and see how engaging in publishable research has impacted their lives. Keeping memorabilia, cards, pictures, or gifts on display in the office can be reminders of rewarding work with students. For some LCPs, certain students may become close friends after graduation and keeping in contact with them may be another reminder of the positive impact of their job. Another strategy is to foster friendships with colleagues who themselves have an optimistic attitude and high commitment to the institution.

\section{REFERENCES}

American Psychological Association (2018). APA Summer Undergraduate Psychology Research Experience Grants. Available online at: https:/www.apa. org/about/awards/undergraduate-research-opportunity.aspx

Baldwin, R. G., and Zeig, M. J. (2013). The Potential of Late-Career Professors. Available online at: https:/www.insidehighered.com/advice/2013/ 05/10/tapping-potential-late-career-professors-essay

Carver, R. P. (1984). Writing a Publishable Research Report: In Education, Psychology, and Related Disciplines. Springfield, IL: Charles C. Thomas Publisher.

Clabough, E. B., and Clabough, S. W. (2016). Using rubrics as a scientific writing instructional method in early stage undergraduate neuroscience study. J. Undergrad. Neurosci. Educ. 15, A85-A93.

Crawford, J. T. (2013). "Engaging students in collaborative psychological research at liberal arts colleges and universities," in So You Landed a Job-What's Next? Advice for Early Career Psychologists from Early Career Psychologists, eds J. Keeley, S. E. Afful, J. J. Stiegler-Balfour, J. Good, and S. Leder. Available online at: http://teachpsych.org/ebooks/ecp2013/index.php
Overall, as they reflect on their tenure at their institution, LCPs who have been teaching and conducting research for many years may well find altruistic motivations for mentoring undergraduates as they begin to focus on the legacy and lasting effects of their careers.

\section{CONCLUSION}

Working on publishable research provides hands-on skill development and close relationships between the undergraduate students and their faculty mentor, which helps those students bring their career aspirations to fruition (Seymour et al., 2004). Given these significant benefits to undergraduate students, it is important to highlight factors (e.g., career stage) that improve faculty's capability and willingness to publish with these students. Though the perspectives shared in this article may have some limitations (e.g., do not include mid-career faculty, do not include male viewpoints), when faculty mentors, no matter the career stage, collaborate with undergraduate students in publishable research, these students reap the benefits including improved cognitive skills and work ethic, increased preparation for graduate school, better career planning, and higher rates of retention (Hunter et al., 2006).

\section{AUTHOR CONTRIBUTIONS}

AM conceptualized the manuscript, composed the ECP section, connected all parts of the paper, conducted the final edits, and completed the submission process. JG worked on the LCP sections and provided general feedback.

\section{FUNDING}

This publication was made possible by the Delaware INBRE program, supported by a grant from the National Institute of General Medical Sciences - NIGMS (P20 GM103446) from the National Institutes of Health and the State of Delaware.

Einarson, M., and Clarkberg, M. (2004). Understanding Faculty Out-ofClass Interaction With Undergraduate Students at a Research University. Ithaca, NY: Cornell Higher Education Research Institute (CHERI), Cornell University.

Fallon, M. (2016). "Writing up quantitative research in the social and behavioral sciences," in Teaching Writing Series, Vol. 6. Rotterdam: Sense Publishers.

Finley, D. (2018). Professional Development Service. Available online at: https:// teachpsych.org/page-1603031

Hunter, A.-B., Laursen, S. L., and Seymour, E. (2006). Becoming a scientist: the role of undergraduate research in students' cognitive, personal, and professional development. Sci. Educ. 97, 36-74. doi: 10.1002/sce. 20173

Keeley, J., Afful, S. E., Stiegler-Balfour, J. J., Good, J. J., and Leder, S. (2013). So You Landed a Job-What's Next? Advice for Early Career Psychologists from Early Career Psychologists. Available online at: http://teachpsych.org/ebooks/ ecp2013/index.php

Lechago, S. A., Love, J. R., and Carr, J. E. (2009). Recommendations for recruiting and managing undergraduate research assistants. Behav. Therapist 32, $120-122$. 
Mabrouk, P. A. (2003). Research learning contracts: a useful took for facilitating successful undergraduate research experiences. Counc. Undergrad. Res. Q. 21, 26-30. Available online at: http://teach.ufl.edu/wp-content/uploads/2016/07/ fall2003_v24.1_mabrouk.pdf

Mamiseishvili, K., and Rosser, V. J. (2010). International and citizen faculty in the United States: an examination of their productivity at research universities. Res. High. Educ. 5, 88-107. doi: 10.1007/s11162-0099145-8

McGuire, M. (2008). An Open Letter to Undergraduate Research Assistants. Available online at: https://www.cs.williams.edu/ morgan/ra.pdf

Narendorf, S. C., Small, E., Cardoso, J. A., Wagner, R. W., and Jennings, S. W. (2015). Managing and mentoring: experiences of assistant professors in working with research assistants. Soc. Work Res. 40, 19-30. doi: $10.1093 /$ swr/svv037

Olsen, D., and Crawford, L. A. (1998). A five-year study of junior faculty expectations about their work. Rev. Higher Educ. 22, 39-54. doi: 10.1353/rhe.1998.0017

Ponjuan, L., Conley, V. M., and Trower, C. (2011). Career stage differences in pretenure track faculty perceptions of professional and personal relationships with colleagues. J. Higher Educ. 82, 319-346. doi: 10.1353/jhe.2011.0015

Psi Chi (2018a). Become a Journal Reviewer! Available online at: https://www. psichi.org/page/JN_BecomeAReviewer\#.W_8FxWhKjcs 240

Psi Chi (2018b). Undergraduate Awards and Grants. Available online at: https:// www.psichi.org/page/1_undergrad_main\#.XCdf2M17nIU
Seymour, E., Hunter, A.-B., Laursen, S., and Deantoni, T. (2004). Establishing the benefits of research experiences for undergraduates in the sciences: first findings from a three-year study. Sci. Educ. 88, 493-534. doi: 10.1002/sce.10131

Shanahan, J. O., Ackley-Holbrook, E., Hall, E., Stewart, K., and Walkington, H. (2015). Ten salient practices of undergraduate research mentors: a review of the literature. Mentor. Tutor. 23, 359-376. doi: 10.1080/13611267.2015.1126162

Society for the Teaching of Psychology (2018). STP Early Career Travel Grant Program. Available online at: http://teachpsych.org/members/grants/ ECPtravel.php

Starke, M. C. (1985). A research practicum: undergraduates as assistants in psychological research. Teach. Psychol. 12, 158-160. doi: $10.1207 /$ s15328023top1203_12

Conflict of Interest Statement: The authors declare that the research was conducted in the absence of any commercial or financial relationships that could be construed as a potential conflict of interest.

Copyright (C) 2019 Mendoza and Golden. This is an open-access article distributed under the terms of the Creative Commons Attribution License (CC BY). The use, distribution or reproduction in other forums is permitted, provided the original author(s) and the copyright owner(s) are credited and that the original publication in this journal is cited, in accordance with accepted academic practice. No use, distribution or reproduction is permitted which does not comply with these terms. 